\title{
Treatment of Stroke in Canadian Emergency Departments: Time to be Leaders
}

\author{
Devin R. Harris, MD, MHSc* ${ }^{\dagger}$; Eddy S. Lang, MD; Jeffery J. Perry, MD, MSc ; Laurie J. Morrison, MD"
}

\section{EDITORIAL}

The debate on effectiveness of thrombolysis in acute ischemic stroke has divided the emergency medicine community since the publication of the NINDS trial in 1995. ${ }^{1}$ This trial was the first to show the effectiveness of treating acute stroke with intravenous alteplase, providing the first therapy that could be administered in emergency departments (EDs) to treat ischemic stroke. However, the merits of this trial, and the risks and benefits of alteplase in stroke, have been hotly debated in the emergency medicine community for the last twenty years. Community-based studies showed that the therapy caused harm, re-analysis of the trial data wasn't as conclusive, and opinion leaders within the emergency medicine community advocated against its widespread adoption. ${ }^{2-4}$ The Canadian Association of Emergency Physicians (CAEP) Position Statement on Thrombolysis for Acute Ischemic Stroke reflected this sentiment in 2000, suggesting alteplase use be limited to research settings. ${ }^{5}$ Since then, many within the emergency medicine community have been passionately against the use of thrombolysis in acute ischemic stroke. This vehement passion against thrombolysis is reflected in what we believe is a biased editorial published in CJEM in April $2015 .^{6}$

This debate regarding the effectiveness of thrombolysis for acute ischemic stroke has resulted in collateral damage. This contrarian viewpoint, although rooted in the best interests of patient safety-that we don't offer a therapy that has significant and lethal side effects-has hindered progress in stroke care within EDs and has limited leadership, collaboration, and engagement.
In many instances, the emergency medicine community has been excluded or has not participated in stroke improvement initiatives, stroke research, or collaboration with stroke specialists, and as a result has most likely affected patient care. There has been a perceived belief amongst emergency physicians that there are limited therapies that may reduce death and disability from acute stroke (an obvious generalization); we have became stroke nihilists. This has extended to the relative passivity with which transient ischemic attacks (TIAs) have been treated within EDs in the past; if this were chest pain, we'd act with urgency, and with a lot more intensity.

In 2016, this is not acceptable. Stroke is preventable, acute stroke is treatable-and emergency physicians should be leaders in this paradigm shift.

Since the NINDS trial was published twentyone years ago, as mentioned in the CAEP editorial, there have been more trials published investigating intravenous thrombolysis for acute ischemic stroke. Certainly, the trials have been plagued by varying patient populations, varying outcome measures, and in the case of IST-3, poor trial design and reporting. ${ }^{7,8}$ It has been confusing for us to compare trials, derive conclusions, and make sense of the conflicting evidence due to the heterogeneity in trial design. However, the CAEP Stroke Committee thoroughly reviewed the literature and published clinical practice guidelines, leading to the current CAEP position statement published in March 2015, strongly supporting the use of thrombolysis for acute ischemic stroke under three hours, due to favourable risk-benefit considerations. ${ }^{\text {? }}$

From the *Department of Emergency Medicine, Kelowna General Hospital, Kelowna, BC; †Department of Emergency Medicine, University of British Columbia, Vancouver, BC; ¥Cumming School of Medicine, University of Calgary, Calgary, AB; §University of Ottawa, Ottawa, ON; and qUniversity of Toronto, Toronto, ON.

Correspondence to: Dr. Devin Harris, Head, Department of Emergency Medicine, Kelowna General Hospital, 2268 Pandosy Avenue, Kelowna, BC, V1Y1T2; Email: Devin.Harris@interiorhealth.ca

(C) Canadian Association of Emergency Physicians

CJEM 2017;19(1):47-49

DOI 10.1017/cem.2016.333 
In 2015 , the thrombolysis landscape shifted further. Since January 2015, five high-quality randomized clinical trials have been published, showing the effectiveness of catheterization and clot removal in acute stroke. ${ }^{10-14}$ These procedures, using stent-retriever devices, were compared against an active placebointravenous thrombolysis. And one of the trials, a Canadian trial, was the first acute interventional stroke trial to show a mortality benefit. ${ }^{10}$ Along with reinforcing that time is the most important determinant for success, the defining characteristic of these trials is how patients were selected for inclusion or intervention. Rather than the crude assessment of eligibility for intravenous thrombolysis that we have been applyingwhich is time since onset and a non-contrast computed tomography (CT) head-these trials used advanced imaging (predominantly CT angiography) for enrolment and eligibility. It is proven now that advanced imaging to determine clot size and location, core (infarct) size, and collateral circulation are much better criteria for selection of patients for thrombolysis. ${ }^{15}$ We have moved from solely time-based criteria for eligibility to tissue-based and time-based criteria.

These trials will and should have a significant impact on emergency practice. Firstly, emergency medical services (EMS) leaders have to be engaged in the discussions relating to patient transport to specialized stroke centers. Bypass, direct transport, and repatriation decisions for stroke patients affect ambulance availability and response times for other calls. Secondly, the imperative of time in treating stroke patients has been reinforced; we need to have streamlined pre-notification, triage, imaging, and referral mechanisms with our departments. Thirdly, we need to be leaders in centers that don't have direct access to stroke teams. We need to identify and treat stroke and TIA patients, or rapidly arrange transfer. This requires clinical skill, experience, and education, and currently our residency programs are not providing enough training in stroke. ${ }^{16}$

Thrombolysis has monopolized the discussion regarding acute stroke care within EDs, but much more can be done for stroke patients-simple and safe interventions - that we should be, but are not, doing consistently. We should give aspirin to all stroke patients who don't have a contraindication. ${ }^{17}$ All our eligible stroke patients should be admitted to stroke units; this unequivocally has the largest impact on morbidity and mortality. ${ }^{18}$ Additionally, we can institute very simple therapies in the ED that make a significant difference: don't insert a urinary catheter, check and treat for hyperthermia, manage patient's glucose levels, perform swallowing screens, and provide prophylaxis for deep vein thrombosis (DVT). ${ }^{19}$ These are simple interventions that, on a population-based level, have a larger impact than thrombolysis. ${ }^{20}$

More importantly, we can prevent stroke. The management of TIAs is now a time-sensitive emergency medicine disorder, to be diagnosed and managed by us. Accurate diagnosis, and application of proven therapies, such as anticoagulation for atrial fibrillation, rapid referral for carotid endarterectomy for symptomatic carotid stenosis, and administration of anti-platelet medications, can reduce the risk of stroke after TIA by up to $80 \% .^{21}$ Current Canadian guidelines advocate that all patients who experience a TIA with symptoms under 48 hours should be seen in an ED immediately; ${ }^{22}$ experts recognize that access to urgent imaging is an imperative, shifting TIA management from an outpatient setting to the ED. ${ }^{23}$ This is unstable angina of the brain; it should be managed with the same urgency as suspected and confirmed acute coronary syndromes.

In the past, we were correct in being cautious to offer thrombolysis for all patients with acute ischemic stroke, because it was harmful if given to the wrong patient. However, we have held onto historical beliefs regarding the ineffectiveness of thrombolysis in stroke, despite increasing evidence supporting its effectiveness. Regardless of our reluctance to embrace acute stroke treatment and secondary prevention as an ED responsibility, stroke mortality has been steadily and significantly declining in Canada. ${ }^{24}$ Currently, there are plenty of opportunities for emergency physicians to improve stroke and TIA care: by taking roles as stroke champions in stroke centers, by improving the quality and depth of stroke education we deliver our residents, or by participating in or leading stroke programs of research. Our involvement could only reduce the burden of stroke on Canadians further.

In 2016, it is time for us to move beyond the thrombolysis debate, and become engaged. It is time for us to be leaders.

Competing Interests: DRH consults for Bayer and Pfizer. The other authors declare no competing interests.

Keywords: stroke, emergency medicine, leadership 


\section{REFERENCES}

1. The National Institute of Neurological Disorders and Stroke rt-PA Stroke Study Group. Tissue Plasminogen Activator for Acute Ischemic Stroke. N Engl 7 Med 1995; 333(24):1581-7.

2. Katzan IL, Furlan AJ, Lloyd LE, et al. Use of tissue-type plasminogen activator for acute ischemic stroke: the Cleveland area experience. $7 A M A$ 2000;283(9):1151-8.

3. Hoffman JR, Schriger DL. A graphic re-analysis of the NINDS trial. Ann Emerg Med 2009;54(3):329-36.

4. Newman DH. Thrombolytics for acute ischemic stroke. The NNT: The NNT Group; 2010. Available from: http://www. thennt.com/thrombolytics-for-stroke (accessed July 2015).

5. Canadian Association of Emergency Physicians Committee on Thrombolytic Therapy for Acute Ischemic Stroke. Thrombolytic therapy for acute ischemic stroke. CFEM 2001;3(1):8-12.

6. Johnstone C. Thrombolysis for acute ischemic stroke: does it work? - the con position. CFEM 2015;17(2):180-3.

7. Hacke $W$, Kaste $M$, Bluhmki E, et al. Thrombolysis with alteplase 3 to 4.5 hours after acute ischemic stroke. $N$ Engl 7 Med 2008;359(13):1317-29.

8. IST-3 Collaborative Group, Sandercock P, Wardlaw JM, et al. The benefits and harms of intravenous thrombolysis with recombinant tissue plasminogen activator within $6 \mathrm{~h}$ of acute ischaemic stroke (the third international stroke trial [IST-3]): a randomised controlled trial. Lancet 2012;379(9834):2352-63.

9. Harris D, Hall C, Lobay K, et al. Canadian Association of Emergency Physicians Position Statement on Acute Ischemic Stroke. CFEM 2015;17(2):217-26.

10. Goyal M, Demchuk AM, Menon BK, et al. Randomized assessment of rapid endovascular treatment of ischemic stroke. N Engl 7 Med 2015;372(11):1019-30.

11. Berkhemer OA, Fransen PSS, Beumer D, et al. A randomized trial of intraarterial treatment for acute ischemic stroke. N Engl 7 Med 2015;372(1):11-20.

12. Campbell BCV, Mitchell PJ, Kleinig TJ, et al. Endovascular therapy for ischemic stroke with perfusion-imaging selection. N Engl 7 Med 2015;372(11):1009-18.
13. Saver JL, Goyal M, Bonafe A, et al. Stent-retriever thrombectomy after intravenous t-PA vs. t-PA alone in stroke. $N$ Engl 7 Med 2015;372(24):2285-95.

14. Jovin TG, Chamorro A, Cobo E, et al. Thrombectomy within 8 hours after symptom onset in ischemic stroke. N Engl 7 Med 2015;372(24):2296-306.

15. Furlan AJ. Endovascular therapy for stroke-it's about time. $N$ Engl 7 Med 2015;372(24):2347-9.

16. Harris D, Teal P, Turton M, et al. Stroke Education in Canadian Emergency Medicine Residency Programs. CFEM 2016;18(4):XXX.

17. Sandercock P, Counsell C, Tseng MC, et al. Oral antiplatelet therapy for acute ischaemic stroke. Cochrane Database Syst Rev 2014;3:CD000029.

18. Stroke Unit Trialists' Collaboration. Organised inpatient (stroke unit) care for stroke. Cochrane Database Syst Rev 2013;9:CD000197.

19. Lindsay P, Bayley M, Hellings C, et al. Canadian best practice recommendations for stroke care: summary (updated 2010). CMA7 2008;17(12 Suppl):S1-25.

20. Langhorne P, de Villiers L, Pandian JD. Applicability of stroke-unit care to low-income and middle-income countries. Lancet Neurol 2012;11(4):341-8.

21. Rothwell PM, Giles MF, Chandratheva A, et al. Effect of urgent treatment of transient ischaemic attack and minor stroke on early recurrent stroke (EXPRESS study): a prospective population-based sequential comparison. Lancet 2007;370(9596):1432-42.

22. Coutts SB, Wein TH, Lindsay MP, et al. Canadian Stroke Best Practice Recommendations: secondary prevention of stroke guidelines, update 2014. Int $\mathcal{F}$ Stroke 2015;10(3): 282-91.

23. Kamal N, Hill MD, Blacquiere DP, et al. Rapid Assessment and Treatment of Transient Ischemic Attacks and Minor Stroke in Canadian Emergency Departments: Time for a Paradigm Shift. Stroke 2015;46(10):2987-90.

24. Kamal N, Lindsay $\mathrm{P}$, Cote R, et al. Ten-year trends in stroke admissions and outcomes in Canada. Can $\mathcal{F}$ Neurol Sci 2015;42(3):168-75. 